Revue bibliographique pour le domaine irano-aryen

\title{
Sara Mondini. «The Use of Quranic Inscriptions in the Bahmani Royal Mausoleums. The Case of Three Tombstones from Ashtur »
}

\section{Viola Allegranzi}

\author{
(2) OpenEdition \\ Journals \\ Édition électronique \\ URL : http://journals.openedition.org/abstractairanica/42589 \\ DOI : 10.4000/abstractairanica.42589 \\ ISBN : 1961-960X \\ ISSN : 1961-960X \\ Éditeur : \\ CNRS (UMR 7528 Mondes iraniens et indiens), Éditions de l'IFRI
}

\section{Référence électronique}

Viola Allegranzi, «Sara Mondini. «The Use of Quranic Inscriptions in the Bahmani Royal Mausoleums.

The Case of Three Tombstones from Ashtur » », Abstracta Iranica [En ligne], Volume 37-38-39 | 2018, document 2, mis en ligne le 10 mars 2018, consulté le 28 septembre 2020. URL : http://

journals.openedition.org/abstractairanica/42589; DOI : https://doi.org/10.4000/abstractairanica 42589

Ce document a été généré automatiquement le 28 septembre 2020.

Tous droits réservés 


\title{
Sara Mondini. «The Use of Quranic Inscriptions in the Bahmani Royal Mausoleums. The Case of Three Tombstones from Ashtur »
}

\author{
Viola Allegranzi
}

\section{RÉFÉRENCE}

Sara Mondini. «The Use of Quranic Inscriptions in the Bahmani Royal Mausoleums. The Case of Three Tombstones from Ashtur », in : Mattia Guidetti et Sara Mondini (eds.), «A mari usque ad mare ». Cultura visuale e materiale dall'Adriatico all'India. Scritti in Memoria di Gianclaudio Macchiarella,(Eurasiatica. Quaderni di Studi su Balcani, Anatolia, Iran, Caucaso e Asia Centrale 4), Venezia, Edizioni Ca' Foscari-Digital Publishing, 2016, p. 203-220 ; accessible en ligne sur : http://edizionicafoscari.unive.it/it/edizioni/libri/ 978-88-6969-086-0/the-use-of-quranic-inscriptions-in-the-bahmani-roy/ (dernière consultation : 19 juin 2017)

1 L'article offre une étude détaillée d'une tombe "mineure » de la nécropole royale d'Ashtoor (district de Bīdār, Karnataka, Inde) qui abrite les sépultures des derniers souverains de la dynastie Bahmanide (1347-1527). Une mission de terrain dans la région a permis à Mondini de (ré)découvrir une chambre funéraire souterraine, qu'elle propose d'attribuer à une période comprise entre la fin du XV et le début du XVI ${ }^{\mathrm{e}}$ siècle. La taille et la forme du cénotaphe suggèrent qu'il s'agit de la sépulture d'une femme, bien qu'aucune donnée historique n'émerge des inscriptions relevées sur le site. En effet, les pierres tombales incluses dans trois niches aveugles à l'intérieur de la chambre funéraire sont entièrement occupées par des citations coraniques (Coran II, 255 ; Coran CXIII, CXIV ; Coran CIX, CXII). L'auteur remarque que la tradition islamique attache une fonction talismanique à chacun des versets cités. Le monument étudié 
apporte ainsi un témoignage de toute importance sur la tradition épigraphique ainsi que sur les croyances répandues au Deccan à l'époque du sultanat Bahmanide.

\section{AUTEURS}

VIOLA ALLEGRANZI

Université Sorbonne Nouvelle, Mondes iranien et indien 